\title{
Functioning of Public Internal Audit in Albania
}

\author{
HYSEN MUCEKU \\ Department of Economics and Finance \\ European University of Tirana \\ Bulevardi Gjergj Fishta, (Ish NPV nr. 2), Tirana, Albania \\ ALBANIA \\ http://www.uet.edu.al \\ KRESHNIK BELLO \\ Department of Management and Marketing \\ European University of Tirana \\ Bulevardi Gjergj Fishta, (Ish NPV nr. 2), Tirana, Albania \\ ALBANIA \\ http://www.uet.edu.al
}

\begin{abstract}
Internal audit is an important tool in helping senior management of organizations to find the right solutions in meeting the objectives. Through findings and recommendations, auditors provide assurance and advice on the management of internal control systems, risk and governance. The management of public organizations in Albania still has an incomplete conception and a low level of awareness on the role of contemporary internal audit services. This is firstly related to the quality of audit activities, where in significant cases the quality of this service is assessed to be not at the levels required by contemporary standards and practices, and secondly to the lack of recognition and misuse of these services by many administrators of public organizations. The aim of this research is to determine the state of capacity of public administration employees in the field of internal audit, in public organizations in Albania and give the right recommendations for the development of these capacities in order for the internal audit service to become a powerful tool in the hands of managers to achieve their objectives by adding value to the organization. The methodology used for the research has its own dimensions such as: specification of research subjects and sampling, tools used for research, implementation plan, ethical issues, presentation of research findings, etc. The research is based on primary and secondary data collection. The research is based on the testing of the Hypothesis, HO. The practical implications of this paper consist in the fact that: this is an in-depth study of the problems faced by the internal audit activity in public sector organizations in Albania. The conclusions and recommendations given to address these issues will add value to the management of these organizations, by helping managers reconsider their roles and responsibilities in order to strengthen the Internal Control System, and to make it a powerful tool in meeting their objectives. They also serve internal auditors to improve their practical activities. The paper is original, as so far in Albania no other studies with these dimensions have been conducted in this field, and it also has both theoretical and practical value for researchers, internal auditors and managers of the field.
\end{abstract}

Key-Words: - Internal audit, Quality assurance, Governance, Objectives, Findings, Recommendations, Reporting, Public organizations in Albania

Received: January 22, 2021. Revised: June 27, 2021. Accepted: July 1, 2021. Published: July 7, 2021.

\section{Introduction}

Contemporary internal audit is conducted as a tool of management with the purpose of increasing the value of the organization by not only reporting the facts, but above all by preventing the occurrence of errors, through the identification of the areas for improvement by the implementation of the best professional practices. Contemporary internal audit, as an independent activity, performs two important functions:

- Firstly, it gives objective assurance on the functioning of internal control systems, governance and risk management.

- Secondly, it provides advice and managerial consultancy. 
In this way these functions add value and improve the organization's activities, helping in the fulfillment of its objectives. Internal audit also brings a systematic and disciplined model, to evaluate and improve effectiveness of risk management, control and governance processes. Internal audit performs a monitoring target placed by management to review and revalidate internal system account, internal controls and risk management, inside the organization.

The internal audit service plays an important role in informing and educating senior management by helping to find the right solutions to meet the objectives, as well as in assisting managers to develop the tools and techniques for governing the organization.

In many countries that have changed from a centralized economy to a market economy, such as Albania, the role and functioning of auditing is still not properly understood. With the support of specialized international bodies (IMF, World Bank, EC), many of these countries are reforming previous public internal financial control structures, in order to establish an independent internal audit function, operating in accordance with the international standards and professional practices of this field.

Creating a culture of risk awareness in the organization is important to establish systems and procedures in which to 'embed' risk management. The 'embedding' of risk management in systems and procedures means that risk management should be an integral part of the managerial practice. Risk management should be a key function that managers, auditors and other employees should consider on a daily basis, in their normal activities.

Effective internal controls should be measurable, in order to be monitored on how they are functioning and to determine a reasonable probability of safety, that guarantees that operations in the organization are successful and that its resources are protected.

\section{Theoretical Overview on the Role of Internal Audit}

The role of testing has advanced to cover nonfinancial areas, and this equates to the internal audit function. A large number of transactions is checked / verified to ensure that they are accurate and properly authorized, as defined in unspecified procedures [23].

Auditors play an important role in the safety and quality of financial information through the opinions and reports they submit. To perform the audit, the information must be in a verifiable form and meet safety and quality standards. To fulfill their purpose, auditors should obtain sufficient and qualitative evidence, determine the types and amount of evidence required, and assess whether the information is in accordance with established standards.

The services of the internal auditors for many years have been related to consulting services and other activities. Internal audit cooperates with management to help it achieve its objectives.

Dealing with dull impact situations, represents one of the biggest challenges that auditors face, not only in terms of acceptance of audit findings, but also from the point of view of relationship management [19].

It is challenging for organizations to assess how effective internal audit activities are and whether benefits have been achieved [25].

Internal auditor and compliance auditor share an important set of common objectives. Working together in the above ways is critical for them to achieve these common goals. They need to meet often, clarify their responsibilities, communicate well and be ready for everyone to take on a supportive role when needed [2].

There is a need to clarify the necessary competencies of internal auditors in general, and those of the Chief Audit Executive (CAE) in particular. Researchers should study disturbing situations in which CAE makes 'strong/harsh/difficult' recommendations without worrying or favoring ('moments of truth'). Scholars should also study the disturbing moments and conflicts that occur when normative guidelines and organizational specifics disagree [15].

Internal auditors provide independent information and assurance that can be used by managers to better assess resource needs and risks and to make better business decisions. In addition, the audit committee and board of directors can use this information to better oversee the performance of managers and provide advice on strategic decisions [14].

The internal audit function is the main government unit with experience in assessing the effectiveness of resource usage, identifying losses, inefficiencies and fraud in budget items [1].

The growth of internal audit in recent years has resulted in an increasing role of oversight of corporate audit committees. Part of this oversight role includes the evaluation of the independence and performance of the internal audit work by the audit committee [24]. 
Essential to combating fraud is having proper internal control procedures that include an appropriate response plan. Internal audit possesses extensive knowledge of the organization's control. A combined security approach is essential in this regard to understand the weaknesses in controls that allow fraud [12].

A charter/statute provides a blueprint for how internal audit will work and allows the governing body to clearly signal the value it places on internal audit independence [13].

As risks increase and become more complex, the role of internal audit is likely to expand into areas such as: risk management, culture and behavior, sustainability, and other non-financial reporting measures [11].

Meanwhile, the use of risk management framework in all enterprises has expanded, while organizations recognize their advantages over less coordinated approaches to risk management. Internal audit, both in its security and in its advisory role, contributes to risk management in a variety of ways [10].

Management has reasonable assurance that, in general, appropriate controls are in place and functioning as intended, risks are being adequately monitored and mitigated, and necessary improvements and reinforcements/supports are being implemented [5].

An integral process, performed by the management and personnel of the entity must be designed/built to address risks, to see/pursue opportunities, and to provide the reasonable assurance to achieve results in the interest of the public and the mission of the unit, through:

- conducting regular, ethical, economic, efficient and effective operations;

- ensuring the relevance, reliability and integrity of information;

- fulfilling the obligations of external and internal responsibility;

- compliance with applicable laws and regulations;

- conservation of resources from loss, misuse and damage;

- meeting other criteria of good public governance, including good policy preparation and implementation, good budgeting and financial strength and sustainability [4].

Within the context of its mission, an organization has been created to meet the objectives. It is assumed that the leaders of the organization can articulate its objectives, develop strategies to achieve these objectives, identify risks to achieve these objectives and then reduce/mitigate these risks in the development/implementation of the strategy [3].

The development and maintenance of efficient management and control systems, based on the principle of decentralized managerial accountability, remains a challenge for public sector managers in EU candidate and potential candidate countries [22].

Risk management is an integral part of the management system of an entity, carried out by the senior management of the entity, managers' line and other personnel, designed to identify, understand and assess potential risks and opportunities (and their interdependence) that may affect the entity, and manage those risks and opportunities that are within the risk appetite/tolerance, in order to provide the appropriate presentation/disclosure and reasonable assurance regarding the achievement of the entity's objectives [21].

Existing risk management standards for listed companies still focus mainly on internal control and audit functions, and financial risk, rather than on identification (ex/ante) and comprehensive risk management. Corporate governance standards should place sufficient emphasis on the prior/ex/ante identification of risks. Attention should be paid to financial and non-financial risks, and risk management should include strategic and operational risks [20].

In order to improve the efficiency and the level of audit work in colleges and universities, it is urgent to improve the quality of audit team in colleges and universities [27].

Internal auditors' attributes were identified as the key for the measurement of internal audit effectiveness, and that the relationships of internal auditors and external auditors, chief audit executives and senior management, play a pivotal role in internal audit effectiveness [28].

Financial pre-warning model plays a vital role in the financial monitoring of one business. It can help management to predict, prevent and control enterprise financial risks [29].

Auditors ensure that financial information is transparent and reliable while supervisors provide confidence in financial system. On the other hand, auditors enable market players to make decisions based on this information and contribute to financial stability [30].

In the overall context of corporate governance and internal auditing, the issue of creating added value plays a central role [31].

Internal control in the public sector in Albania is generally considered weak, because some of the 
components, elements and units that enable an effective internal control are missing [26].

This literature review shows the possible dimensions of how internal audit can create added value through its services, and of how this value can be measured

\section{Study Methodology}

This paper will address the role of internal audit in the activities of public organizations in Albania, and the main problems faced by internal audit in the public sector of Albania, providing the necessary recommendations for strengthening the role of internal audit in the management of activities of these organizations, and for increasing of the managerial accountability.

In order to identify the problems faced by public internal audit in Albania and to assess the capacity of this service, for the purposes of our study, the method used in data collection is the quantitative one, developed in the form of an online questionnaire, as well as the qualitative one, developed in the form of semi-structured interviews. For the data analysis, both these sources of information are complementary, in order to ensure that the findings describe certain prevailing phenomena.

The methodology used for the research has its own dimensions specified as: purpose and objectives of research, definition of hypothesis, specification of research subjects and sampling, tools used for research, implementation plan, ethical issues, practical implications of research, originality and value of study, and presentation of study results.

\subsection{Purpose and Objectives of Research}

The aim of this study is to determine the state of capacity of public administration employees in the field of internal audit.

The main objectives of this paper are to identify:

- The role of internal audit in providing assurance on the functioning of internal control systems in public organizations.

- The impact that security and internal audit consulting activities have on strengthening the governance systems of the public organization.

- The main problems faced by internal audit in public sector organizations in Albania, provide the relevant recommendations for solution, and increase the efficiency of audit activities.

\subsection{Definition of Hypothesis}

The research is based on testing of the Hypothesis $H O$, expressed as: Quality internal audit services do not play an important role in the performance of the activities of public organizations in Albania.

Firstly, there can be a direct measurement of competencies, through different types of tests (e.g., written testing of knowledge and skills, performance tests, etc.), or through the analysis of the results of people's work.

Secondly, there can be an indirect (less direct) way which relies on competency reporting - one way to do it is self-reporting, i.e., employees themselves evaluate and measure their competencies. Given the sensitivity of measuring professional competencies at work, especially for civil servants, it was decided to use the less direct method, which is self-reporting.

Thirdly, the issues in the questionnaire were not defined in the form of competencies, but in the form of specific work practices, on which the participants assessed the need for further professional development. This also helped to reassure the participants that the activity is not an evaluation of their work.

\subsection{Specification of Research Subjects and Sampling}

After defining the hypothesis, we started out the work about specification of research subjects and sampling that could be compatible to the purpose of this research.

The target population for this research were public internal auditors. The sample was limited to internal auditors of the central administration, which included four types of institutions: ministries, authorities integrated within ministries, special organizations, and government service offices. The sampling for the study was a non-probability one the general approach was to cover the wide range of central public institutions and to involve relevant staff in the research.

The sample used for the audit civil servants was composed of 98 individuals and could be considered as representative for the given population of 410 public auditors in total. At the same time, the qualitative part of the research strongly confirmed many of the findings of the quantitative survey, thus providing an argument that the survey findings could be considered valid.

The sample used in the qualitative part of the interviews was composed of 10 civil servants leading the executive audit. The selection of respondents was based on the following rule: if a ministry has an organizational unit for internal audit, 
then the head of this unit should be selected for the interview.

In this section, the data on the main professional characteristics of the survey participants were also described. Other information about the sample relates to the type of central public administration institution where the respondents were employed. Most internal auditors worked in an integrated authority within a given ministry.

\subsection{Tools Used for Research}

In order to collect the necessary information, analyze the data, and draw conclusions, the semistructured interviews and the questionnaires (3 questionnaires) were used. The analyses of the collected information would give us the necessary level of understanding about the issue in discussion.

The qualitative part of data collection was done in the form of semi-structured interviews with the purpose of doing a more in-depth study of the phenomenon described above. The aim was to achieve the perceived purpose and personal insight that audit civil servants adhere to approaches of public administration development - all areas that were investigated in the survey were present as topics in the interviews. The focus of the interviews was placed on the perceptions of these processes as a whole and on their specific elements in terms of: 1) effectiveness, 2) greater challenges, and 3) competencies that need to be improved in order to be more effective in their tasks.

The questionnaires were prepared to collect (quantitative) important data on different aspects of the special practices performed by internal auditors, their professional qualification and development. The questionnaires were administered only for internal auditors in public organizations, and they only asked about the perceptions of professional development needs for changes in internal audit practices. It was assumed that all practices are appropriate for internal auditors, as they represent the standard job description for them. However, respondents had the possibility to indicate whether a certain practice, in their opinion, was not relevant to their work.

The questionnaires included questions on the professional development required for internal audit planning, namely: the preparation of strategic plans for internal audit, annual work plans and risk-based engagement programs. Here are also assessed the professional development needs, in terms of establishing internal audit policies and procedures, and preparatory activities such as communicating the internal audit plan with senior management. There are also addressed the basic assessments of the organization's objectives - their ethical aspects, alignment with the organization's mission, and the role of information technology in meeting the objectives.

The questionnaires also asked internal auditors about planning and performing individual internal audit engagement - setting objectives, scope, timing, and resource allocations to identify and document the relevant information, in order to support conclusions.

Other questions cover the professional development needs in relation to the preparation of audit reports with conclusions, recommendations, and action plans recommending control activities for the management and monitoring of followup/accompanying activities.

Other questions dealt with the professional development needs for performing different types of internal audit: compliance audit, performance audit, IT systems audit, financial audit and auditing of EU funded programs.

\subsection{Implementation Plan}

The way we were organized helped us in reducing the time and costs required to perform the interviews and collect the questionnaires. Data were collected during the years 2019-2020, comprising a period of (last) five years.

The primary data were collected (a part of the primary data was collected in the framework of the FINAC Project (Financial Management, Accounting and Controlling in Public Administration, program of the European Union ERASMUS +), which was implemented in Albania in 2017-2019 [6], [7], [8], [9]), whereas the secondary data used in the study were mainly collected from published manuals, methodologies and reports of the Ministry of Finance of the Republic of Albania [16], [17], [18].

Collected data were processed, in order to prepare the findings and draw conclusions. There were not present any difficulties in conducting the interviews and distributing and collecting the questionnaires.

\subsection{Ethical Issues}

The information collected from the respondents was very important for analyzing and interpreting the findings. The names of the respondents due to ethical obligations, were not disclosed in this paper.

\section{Presentation of Study Results}

In this section the results of the study are presented. 


\subsection{Empirical Study Results}

The data collection for the empirical study was conducted through the on-line questionnaires sent to internal auditors. The three prepared questionnaires (receiving data on: (1) General information, (2) Information on the qualification of internal auditors, (3) Information on the professional development needs of internal auditors) identified 74 specific practices performed by internal auditors based on professional standards and practice. The given answers were administered in tabular way, where for each group of questions and answers were prepared separate tables (16 tables). The analysis of the data collected showed that:

Internal auditors in particular, express the need for professional development, in performing performance auditing (81\% of respondents express high/moderate need), in performing information system audit $(90 \%$ of respondents express high/moderate need), and in conducting audits of programs and projects funded by the European Union (90\% of respondents express high/moderate need). In addition to these (being the highest development priorities), below is given a list of practices for which more than $70 \%$ of auditors highlighted the high/moderate level of need for professional development, namely:

- Creating a risk-based plan to set the priorities of the internal audit activity, in accordance with the goals of the organization.

- Assessing whether the organization's information technology governance supports the organization's strategies and objectives.

- Assessing whether significant risks are identified and assessed by the organization.

- Assessing whether the appropriate risk responses related to the organization's risk/appetite for risk are selected.

- Assessing risk exposures related to the achievement of the organization's strategic objectives and the reliability and integrity of financial and operational information.

- Assessing the possibility/potential for fraud to occur and how the organization manages fraud risk.

- Assessing the adequacy and effectiveness of controls in response to risks related to: the achievement of the organization's strategic objectives, the reliability and integrity of financial and operational information, the effectiveness and efficiency of operations and programs.
- Working with management to develop appropriate evaluation criteria for governance evaluation, risk management and controls.

- Reviewing of public procurement procedures.

- Reviewing whether the activities of the local departments responsible for human resource management are adequately designed, assigned and performed.

- Reviewing whether there are adequate procedures for monitoring, improving and rewarding performance in the organization.

- Using of the observation and investigation techniques.

\subsection{Qualitative Analysis Results}

The data for the qualitative analysis were obtained through interviews conducted by the authors with 10 heads of internal audit units of public organizations. To conduct the interviews, the authors prepared in advance a list of questions (18 questions) that was focused on the functioning of internal audit in the public sector (covering issues like: purpose, authority, responsibility, independence and objectivity of internal audit). The conducted interviews were recorded in order to document the results of the study. From these interviews were found:

The management of organizations in Albania still has an incomplete conception and a low awareness of the role that contemporary audit services have. This is related to the quality of audit activities, where in many cases they are not evaluated in compliance with the contemporary standards, and to the lack of knowledge about the role of these services from many leaders of organizations.

In many cases it is indicated violation of functional independence of auditors by managers of organizations starting from the programming of audit activities until their implementation.

Also, it is noticed a limited role of auditors in keeping records - that is, not giving appropriate recommendations for the improvement of the systems, in order to avoid negative events become ordinary phenomena. In many cases it is indicated, a non-accurate recording of findings, incomplete training on how to observe, giving of inappropriate and unenforceable recommendations, which bring negative impact on the results of work and on the quality of audit activity.

Communication of the audit results and the exchange of information between the organizations remains one of the weakest points of the system, 
especially when it comes to public governance units. Findings and recommendations are necessary for the line management in the audited field, because through their findings and recommendations, it is added value to the organization's activity.

On the other hand, for the leaders of organizations, the concepts of "risk management" and "establishment of controls precisely in response to them" still remains unresolved.

A key question that arises in auditing activities is: Can the external auditors rely on the work of the internal auditors? The answer to this question depends on many variables like: whether internal auditors are independent from management, whether the unit has enough and capable auditing staff, whether their activity is done complying to work standards and therefore can be reliable, whether their work is based on independent systems (safety may change). To better answer this question another questionnaire can be used.

While the accountability and objectives of the external and internal auditors may differ, they have common interests, which means that their work often overlaps.

If the external auditor decides to use the work performed by internal audit, he/she has a responsibility to express an opinion on the audit and that responsibility is not limited by the use of internal audit work. All judgments relating to the audit of the financial statements are those presented by the external auditors.

Further findings from the analysis of interviews indicate that compliance audit is the most developed type of audit in the Albanian public administration.

It is necessary, as suggested by the respondents, to provide detailed and specific recommendations and to distinguish between recommendations on financial transactions and recommendations on the overall performance of financial systems.

Also, what is needed is to focus the audit on the causes of the identified problems and provide useful recommendations for resolving the identified problems.

Performance auditing and IT auditing is a major challenge that requires the development of audit capacity. Information systems audit programs and audit programs of EU funded projects are still in the pilot phase in Albania, so new methodologies are being implemented. In regard with the information system audit, the digitalization process in public administration requires intensive capacity development for the audit of all types of information systems.

Another topic in the interview with the internal auditors was the use of various tests and audit techniques. The overall indication is that there is a need to adopt new audit techniques and develop existing ones (such as interviewing), as reported by some of the internal auditors interviewed.

Finally, internal auditors were asked to provide feedback on reporting and communicating internal audit results and recommendations to senior management and follow-up (progress monitoring). It is noted that progress has been made when it comes to communicating results and recommendations. But, there are some areas where further developments are needed, such as training on how to analyze the causes of problems and how to draw conclusions and recommendations on these problems, that should be specific recommendations. Moreover, there is a need to improve the reporting language - it should be simple, clear and accurate.

Based on the findings of the study, it results that the hypothesis HO: Quality internal audit services do not play an important role in the performance of the activities of public organizations in Albania; is invalidated, that is, alternative hypothesis $\mathrm{Ha}$ : Quality internal audit services play an important role in the performance of the activities of public organizations in Albania; is validated, and this means that the performance of the governance of public organizations increases by increasing the quality of internal audit activities.

\section{Conclusions and Recommendations}

Conclusions and the recommendations for each conclusion (recommendations in italics) are given below:

In the exercise of audit activities of public organizations in Albania, in many cases there is a violation of the functional independence of the auditor by managers starting from the programming of audit activities until their implementation and reporting.

The limited role of the auditor is ascertained. So, by not giving the necessary recommendations for the improvement of the systems is impossible to avoid that negative events turn into common phenomena. In many cases, inaccurate records of findings are found, incomplete treatment of observations, often leading to inappropriate and inapplicable recommendations, which have negative impacts on the results of work and the quality of audit activity.

Communication of audit results, and exchange of information between organizations remains one of the weakest points of the system when it comes to public governance units in particular. 
Ensuring a high level of quality of the audit activity still remains a very acute problem that is continuously posed for solution, both in the audit activity of public entities, as well as in the framework of the entire audit system in Albania.

Establishment and functioning of a program for quality assurance of audit activities, which consists in the development of the existing regulatory framework, theoretical and practical, as well as in the building of professional audit capacities will promote the increase of the level of work in audits.

Risk assessment remains a little developed process in the methodologies applied in practice by auditors. Concrete cases of risk assessment are sporadic and have not yet become common practice of audit work. On the other hand, for the leaders of organizations, the concept of "risk management" and the "establishment of controls precisely in response to them" remains an unresolved issue.

Developing risk-based audit strategies for evaluating the activity of organizations and training auditors with practical methods for risk assessment and treatment would greatly increase the efficiency of this activity. Based on the definition of the areas with the highest risk, the audit structures also set their priorities.

Another important element is the authority of the audit body, who should have full and unrestricted access to all activities within an organization.

Auditors should have the authority to obtain information and explanations that they deem necessary to meet their objectives and responsibilities. Auditors should also have the authority to ask management for a response within a timely manner to any findings or recommendations included in their work.

Accurate and complete definition of the object of audit engagement has an important impact on the efficiency of the audit activity.

The engagement program: should include, existing policies; procedures and activities; monitor the achievement of the organization's objectives; identify, assess and manage the risk of the organization in meeting its objectives. Also during the engagement, the auditors should advise and evaluate policies within the responsibilities of the head of the organization, as well as evaluate economical, efficient and effective use of resources.

The modern audit service is an important tool in the hands of managers of organizations in meeting their objectives. For questions like: why should you rely on audit services?, and where should you rely?, the answer is:

Contemporary audit activity is increasingly oriented towards performance audits. In Albania this type of audit is performed in very few audit activities. Organizations today face significant challenges such as: (1) how to ensure low-cost resources and the right quality and standards; (2) using available resources with appropriate efficiency; and (3) meeting the set objectives (achieving the intended results).

An auditor who has a good knowledge of the governance of the organization plays an important role in ensuring the consistency and success of the organization.

Auditors also play an advisory role that helps the organization to design and establish the necessary infrastructure of the organization especially the internal control system.

While the role of providing reasonable assurance helps to ensure that internal control structures are well understood by managers, it is important to assure that these control structures function well. It is difficult to talk about risk management if we are not talking about internal control, and both of these essential aspects ensure the success of the organization.

Audit Committees (AC) have an important role in the audit activity. The role of ACs is already recognized in the activity of organizations and they are becoming mandatory for large organizations, but for smaller organizations their functioning is recommended.

In the audit process importance is given to the provision of management recommendations, which aim to improve the internal control systems and activities of the organization in order to achieve the objectives. Organizations should improve:

The decision-making processes of policy-making and implementation of procedures, definition of strategies and objectives in audited organizations.

The internal and external legal and procedural framework that directs the activity of organizations (establishing procedures, clear rules for the prevention of negative phenomena, verifications, authorizations, division of tasks according to functions, roles and responsibilities).

The financial management systems in order to ensure economical, efficient and effective use of funds (increase the quality of budget planning and implementation, establish careful rules to prevent fraud and theft, safeguarding assets, etc.).

The professional development of employees in the organization and especially of the staff working in financial management structures, as well as the establishment and professional development of audit capacities.

The strategic objective of the audit is to provide recommendations for improving the system and 
adding value to the organization. The achievement of this objective is largely determined by the quality and applicability of the recommendations, which shows the responsibility of audit in finding the most effective ways to raise the awareness of the management of organizations on the value and benefits of implementing the recommendations.

For this reason, the evaluation of the audit activity is not limited to the given recommendations, but it also considers the indicators of importance and the degree of implementation of the recommendations.

\section{References:}

[1] Aikins, S. K., An Examination of the Role of Government Internal Audit in Improving Financial Performance, Public Finance and Management, Vol. 11, No. 4, 2011, pp. 306337.

[2] Chen, S., How can internal audit work with compliance to increase value, Journal of Internal Audit, Winter 2019.

[3] Committee of Sponsoring Organizations / COSO, Improving organizational performance and governance, 2014.

[4] European Commission, Principles of Public Internal Control, 2015.

[5] European Commission, Annual Activity Report. Internal Audit Service (DG IAS). Ref. Ares (2020) 1829653, 2019.

[6] FINAC, Research Report (Draft) 1.2: Albania. Mapping of current qualification structure of public administration employees in financial management, accounting and control activities, 2017.

[7] FINAC, Research Report (Draft) 1.3: Albania. Teaching outcomes and harmonization of national strategies and EU directives in public administration, 2017.

[8] FINAC, Research Report (Draft) 1.4: Albania. Mapping of knowledge and expertise of trainers at the regional partner universities, 2017.

[9] FINanacial management, Accounting and Controlling curricula development for capacity building of public administration / FINAC, Research Report (Draft) 1.1: Albania. Mapping of current level of knowledge of employees in public administration in the field of financial management, accounting and control, 2017.

[10] Institute of Internal Auditors / IIA, Position Document IIA. The Role of Internal Audit in Enterprise Risk Management, 2009.
[11] Institute of Internal Auditors / IIA, Position Document IIA. The Role of Internal Audit in Corporate Governance, 2018.

[12] Institute of Internal Auditors / IIA, Position Document IIA. Fraud and Internal Audit. Security Over Fraud Controls Essential to Success, 2019.

[13] Institute of Internal Auditors / IIA, Position Document IIA. Internal Audit Charter, 2019.

[14] Jiang, L., André, P., Richard, C., An international study of the quality of the internal audit function, Accounting and Business Research, 2017.

[15] Lenz, R., Sarens, G., \& Jeppesen, K.K., Looking for a measure of effectiveness for internal audit functions: an institutional perspective, 2018.

[16] Ministry of Finance of the Republic of Albania, Manual for Financial Management and Control, 2016.

[17] Ministry of Finance of the Republic of Albania, Internal Audit Manual, 2016.

[18] Ministry of Finance of the Republic of Albania, Methodology for external quality assessment, On internal audit activity in the public sector. Methodology developed by the Directorate of Internal Audit Harmonization, based on the publication of PEMPAL IACOP 1, Quality Assessment Guide for Internal Audit in the Public Sector, 2017.

[19] Nuijten, A., Keil, M., Sarens, G., Van T. M., Partners or opponents. The dynamics of the audit-manager relationship after the dull impact on the information system projects, Journal of Management Audit, Vol. 34 No. 9, 2019, pp. 1073-1100.

[20] OECD, Risk Management and Corporate Governance, 2014.

[21] OECD, Public Sector Integrity Survey. Internal control and risk management, 2016.

[22] Organization for Economic Co-operation and Development / OECD, SIGMA PAPER No.59, Guidelines for quality assessment of internal control systems, 2019.

[23] Pickett, K. H. S., The Essential Handbook of Internal Auditing, John Wiley and Sons, Ltd., Publication, 2010.

[24] Schneider, A., Evaluation of internal audit by audit committees, 2010.

[25] Turetken, O., Jethefer, S., Ozkan, B., Internal Audit Effectiveness: Operationalization and Impact Factors, Journal of Managerial Audit, 2019.

[26] USAID, Internal Control (Guide for Managers), 2009. 
[27] Wenlei, Ch., Research on the Path of Building Audit Team in Colleges and Universities in the New Period, Advances in Social Science, Education and Humanities Research, volume 336, 2019, pg.705- 708 .

[28] Edward, Y., Critical Literature Review on Internal Audit Effectiveness, Open Journal of Business and Management, pg.1977-1987, 2020

[29] Zhuo, Zh., Jiang, W., Financial, Model Based on Principle Component Analysis and Support Vector Machine, International Journal of Circuits, Systems and Signal Processing, Volume 13, pg.183-190, 2019.

[30] Valbona, C., Manuela, M., Artur, R., Ilda, K., The need for improvement of External Audit Reports of banks (The case of banks in Albania which mainly belong to EU Banks), WSEAS Transactions on Environment and Development, Volume 16, pg. 539-547, 2020.

[31] Anna, E., Marc, E., What is the value of internal auditing? - A literature review on qualitative and quantitative perspectives, Maandblad voor Accountancy en Bedrijfseconomie 94(3/4), pg.83-92, 2020.

Contribution of Individual Authors to the Creation if a Scientific Article (Ghostwriting Policy)

\section{Author Contributions:}

Hysen Muceku carried out the Conceptualization and Formal analysis, and was responsible for the Methodology development, Resources and Writing of the original draft.

Kreshnik Bello was responsible for the Investigation process, Methodology development and the Validation of results.

Follow: www.wseas.org/multimedia/contributorrole-instruction.pdf

\section{Sources of Funding for Research Presented in a Scientific Article or Scientific Article Itself}

The study was funded by the authors of the paper. One of the authors, Mr. Muceku, was a member of the FINAC project, therefore for the purposes of the study there were used and analyzed (by the author) data collected in the framework of this project as well. However, there is no conflict of interest.
Creative Commons Attribution License 4.0 (Attribution 4.0 International, CC BY 4.0) This article is published under the terms of the Creative Commons Attribution License 4.0 https://creativecommons.org/licenses/by/4.0/deed.en US 